\title{
Vaginal cuff dehiscence after laparoscopic trachelectomy post hysterectomy: a case report and brief review of the literature
}

\author{
Sotirios Kalogeropoulos ${ }^{1}$, Elpiniki Chronopoulou ${ }^{1 *}$, Evangelos Iliopoulos $^{2}$, Georgios Decavalas $^{1}$
}

\begin{abstract}
${ }^{1}$ Department of Obstetrics and Gynecology, ${ }^{2}$ Department of General Surgery, University General Hospital of Patras,
\end{abstract} Patras, Greece

Received: 01 September 2018

Accepted: 13 November 2018

\section{*Correspondence:}

Dr. Elpiniki Chronopoulou,

E-mail: elpiniki.chronopoulou.12@alumni.ucl.ac.uk

Copyright: (c) the author(s), publisher and licensee Medip Academy. This is an open-access article distributed under the terms of the Creative Commons Attribution Non-Commercial License, which permits unrestricted non-commercial use, distribution, and reproduction in any medium, provided the original work is properly cited.

\begin{abstract}
Vaginal cuff dehiscence (VCD) is a serious complication of total laparoscopic hysterectomy (TLH) or trachelectomy with high morbidity, as it can potentially lead to evisceration/bowel ischemia and sepsis. Authors present a case report of vaginal cuff dehiscence after laparoscopic trachelectomy. The patient reported post-coital onset of symptoms. She presented with acute abdomen and required urgent surgical intervention. In this case surgical management was dictated by the clinical manifestation. However, authors argue that conservative management is also an option for some of these patients and the decision regarding the management plan should be personalized according to the clinical presentation and the patient's expectations. Emphasis should be given to avoid early onset of sexual activity during the immediate recovery period. Compared to women who underwent an abdominal or vaginal hysterectomy, those who had a laparoscopic procedure have less post-operative pain, shorter recovery period and often they are advised to return early to their normal habits and their work place. It is expected that this group of patients feel well enough to resume sexual activity soon after their procedure. Therefore, our counselling is of paramount importance as it should be highlighted that sexual intercourse is possibly the most common triggering event for VCD which a serious complication with severe morbidity is. The resumption should, therefore, follow medical consultation and be individualized according to co-morbidities which could affect healing, intraoperative findings and evaluation of the whole recovery progress.
\end{abstract}

Keywords: Laparoscopy, Laparoscopic hysterectomy, Laparoscopic trachelectomy, Vaginal cuff dehiscence

\section{INTRODUCTION}

Hysterectomy is a very common gynecologic procedure and is moving more and more towards the minimally invasive field. Vaginal cuff dehiscence (VCD) is a serious complication of hysterectomy with high morbidity. Presentation varies from a small opening in the vagina wound to serious evisceration evisceration/bowel ischemia and sepsis. The incidence of VCD has increased during the last decades as total laparoscopic hysterectomies (TLH) and trachelectomies with laparoscopic closure of the vaginal cuff have become routine. ${ }^{1}$ However, it is poorly discussed in the literature, with mostly case reports or case series with most studies being underpowered with heterogeneity and lack of comparison groups. ${ }^{2}$ There are numerous factors which have been associated with VCD, such as vaginal opening and closing techniques, the use of electrocoagulation, duration of the procedure, experience of the surgeon, postoperative infection or hematomas, patient characteristics and patient conformity during the recovery period (straining, weight lifting, early onset of sexual intercourse etc). Trying to minimize the impact of this complication one should consider reducing as much as possible the use of thermal energy, possibly use delayed absorbable sutures with adequate tissue bites and 
provide evidence-based counseling to patients in order to ensure uncomplicated recovery period and increased awareness for early recognition and management.

Authors present a case report of vaginal cuff dehiscence after laparoscopic trachelectomy aiming to increase clinical awareness and to emphasize that patients should receive counseling in order to avoid early onset of sexual activity during the immediate recovery period.

\section{CASE REPORT}

A 45-year-old patient attended the Emergency Department of Patras University Hospital due to severe abdominal pain. The pain had started a week ago and progressively worsened. She was a heavy smoker (one pack/day) and had no significant past medical history. She had one emergency caesarean section in the past due to preeclampsia. Her surgical history included a laparoscopy for endometriosis five years ago and a laparoscopic hysterectomy two years ago due to fibroids. She was now on day 32 post laparoscopic trachelectomy with unilateral oophorectomy due to two large persistent endometriomata. The patient had an uncomplicated immediate recovery period and was discharged on day three. She resumed sexual activity on day 22. She subsequently noticed smelly vaginal watery discharge and later on vaginal bleeding which she was advised to be normal.

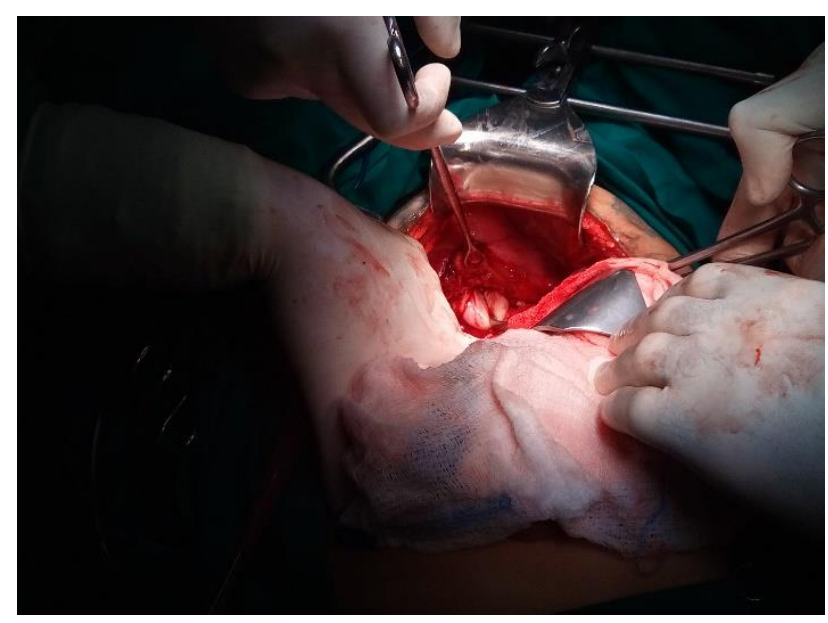

Figure 1: Intraoperative image of vaginal cuff dehiscence.

She presented to us with a clinical image of acute abdomen and diffuse peritonism. On abdominal Xray there was air under the diaphragm and she was taken to theatre as an emergency for an exploratory laparotomy. The only remarkable laboratory findings were WBC of 18000 and CRP of 30. Intraoperatively a VCD was noticed which was repaired with interrupted stitches (Figure 1). She was assessed from the infectious disease team and received a course of meropenem, vancomycin and teicoplanin. She was discharged on day 7 on oral antibiotics and recovered well.

\section{DISCUSSION}

The incidence of VCD is higher and it occurs sooner in the laparoscopic/robotic hysterectomy compared with the abdominal or vaginal approach and has been documented between 1.7 and $4.1 \%$. 3,4 Potential explanations are thermal damage during laparoscopy or false perception of magnified image leading to flawed vaginal suture. ${ }^{5,6}$ Presenting symptoms could be vaginal bleeding/ discharge, dysuria, abdominal pain or vaginal mass in case of evisceration. Possible causes include factors related with the patient, factors related with the technique and incidents which influence the recovery progress. The modality of cuff closure may contribute to the incidence of VCD however this is once more a point of controversy. The transvaginal suturing technique has been associated with significant reduction of the risk compared with laparoscopic and robotic sutures in a study including more than 12,000 patients and a recent case series. ${ }^{6,7}$ This finding has, however, been questioned. ${ }^{8}$ Radical hysterectomy is associated with higher risk. ${ }^{4}$

Barbed suture appeared to be protective in a recent metaanalysis. ${ }^{9}$ The use of unidirectional barbed suture without backward stitching also appears to be safe for the vaginal cuff closure in a recent retrospective study. ${ }^{10}$ The surgical experience and expertise is of great importance, as expected. ${ }^{5}$ However, when comparing procedures performed by trainees or specialists, the rate of major complications requiring reoperation remained the same. ${ }^{11}$ The use of laser angiography during robotic hysterectomy to assess the perfusion of the vaginal cuff and guide intraoperative decisions has been assessed in a feasibility trial including 20 women recently with good results. ${ }^{12}$

Vaginal atrophy, co-morbidities that influence the healing process, increased age, smoking, radiation treatment, hysterectomy due to malignancy and infection have also been reported as risk factors for VCD. ${ }^{6}$ Precipitating causes include early onset of sexual intercourse (commonest precipitating factor for young patients as in present case), and increased intra-abdominal pressure as during defecation/ Valsava Maneuver. ${ }^{13}$ However, the incidence of spontaneous VCD without any precipitating factors is as high as 70\%. ${ }^{4}$ There is no evidence-based recommendation regarding the time to restart coitus. Most hospitals worldwide advise the patients to avoid intercourse for at least 8-12 weeks, and in some cases, mainly oncologic, up to 3 months.

Evisceration in VCD cases has been reported to be as common as $70 \%$ and is an absolute indication for surgical management (vaginal, abdominal, laparoscopic or combined). ${ }^{2}$ Nevertheless in cases of dehiscence without bowel involvement, conservative management is an alternative for a significant proportion of cases. ${ }^{14}$ However, this is rarely chosen as the preferred management option and there is very limited relevant evidence as it is poorly reported in the literature. 
Conservative management aims to avoid the physical and emotional impact of a second operation but requires excellent communication with the patient, good conformity to treatment and adherence to the long and close follow up.

\section{CONCLUSION}

In conclusion, when VCD without evisceration occurs, conservative management should be considered as a treatment option in order to avoid a second operation. However, the management plan should be dictated by the clinical presentation, as sometimes surgical intervention is necessary (as in present case since the patient presented with acute abdomen). The alternatives should be thoroughly discussed with the patient in order to develop a personalized approach taking into consideration the patient's wishes and expectations-risks of surgery versus conservative management with longer recovery/ follow up time and possibly longer hospitalization period and sometimes need for delayed operation.

\section{Funding: No funding sources}

Conflict of interest: None declared

Ethical approval: Not required

\section{REFERENCES}

1. Ala-Nissila S, Laurikainen E, Makinen J, Jokimaa V. Vaginal cuff dehiscence is observed in a higher rate after total laparoscopic hysterectomy compared with other types of hysterectomy. Acta Obstet Gynecol Scand. 2018;10:13459.

2. Cronin B, Sung VW, Matteson KA. Vaginal cuff dehiscence: risk factors and management. Am J Obstet Gynecol. 2012;4:284-8.

3. Kho RM, Akl MN, Cornella JL, Magtibay PM, Wechter ME, Magrina JF. Incidence and characteristics of patients with vaginal cuff dehiscence after robotic procedures. Obstet Gynecol. 2009;114:231-5.

4. Nick AM, Lange J, Frumovitz M, Soliman PT, Schmeler KM, Schlumbrecht MP, et al. Rate of vaginal cuff separation following laparoscopic or robotic hysterectomy. Gynecol Oncol. 2011;120:4751 .

5. Hur HC, Donnellan N, Mansuria S, Barber RE, Guido R, Lee T. Vaginal cuff dehiscence after different modes of hysterectomy. Obstet Gynecol. 2011;118:794-801.
6. Uccella S, Ceccaroni M, Cromi A, Malzoni M, Berretta R, De Iaco P, et al. Vaginal cuff dehiscence in a series of 12,398 hysterectomies: effect of different types of colpotomy and vaginal closure. Obstet Gynecol. 2012;120:516-23.

7. Aydogmus H, Aydogmus S, Gencdal S, Kelekci S. Cuff closure by vaginal route in TLH: case series and review of literature. J Clin Diagn Res. 2017;11:3.

8. Kim MJ, Kim S, Bae HS, Lee JK, Lee NW, Song JY. Evaluation of risk factors of vaginal cuff dehiscence after hysterectomy. Obstet Gynecol Sci. 2014;57:136-43.

9. Uccella S, Casarin J, Marconi N, Gisone B, Sturla D, Alluvion $\mathrm{CP}$, et al. Incidence and prevention of vaginal cuff dehiscence following laparoscopic and robotic hysterectomy: a systematic review and metaanalysis. J Minim Invasive Gynecol. 2015;22:S40.

10. Misirlioglu S, Boza A, Arslan T, Urman B, Taskiran C. Unidirectional barbed suture for vaginal cuff closure without backward stitch in total laparoscopic hysterectomy. J Obstet Gynaecol Res. 2018;44:17939.

11. Jokinen E, Brummer $\mathrm{T}$, Jalkanen $\mathrm{J}$, Fraser $\mathrm{J}$, Heikkinen AM, Mäkinen J, et al. Hysterectomies in Finland in 1990-2012: comparison of outcomes between trainees and specialists. Acta Obstet Gynecol Scand. 2015;94:701-7.

12. Beran BD, Shockley M, Padilla PF, Farag S, Escobar $\mathrm{P}$, Zimberg S, et al. Laser angiography to assess the vaginal cuff during robotic hysterectomy. JSLS. 2018;22:e2018.00001.

13. Iaco PD, Ceccaroni M, Alboni C, Roset B, Sansovini M, D'Alessandro L, et al. Transvaginal evisceration after hysterectomy: is vaginal cuff closure associated with a reduced risk?, Eur J Obstet Gynecol Reprod Biol, 2006;125:134-8.

14. Hamal S, Hui JW, Rong WX, Hui L. Evaluation of post hysterectomy vaginal cuff related complications and their management after different modes of hysterectomy. Int $\mathbf{J}$ Reprod Contracept Obstet Gynecol. 2017;4(2):447-52.

Cite this article as: Kalogeropoulos $\mathrm{S}$,

Chronopoulou E, Iliopoulos E, Decavalas G. Vaginal cuff dehiscence after laparoscopic trachelectomy post hysterectomy: a case report and brief review of the literature. Int J Reprod Contracept Obstet Gynecol 2018;7:5204-6. 